\title{
Evaluation of posterior segment manifestations following typhoid fever-a clinical study
}

\author{
Pavana Acharya ${ }^{1}$, Lakshmi Bomalapura Ramamurthy ${ }^{2, *}$, Kavitha Chikkanayakanahalli Venugopal ${ }^{3}$, \\ Sahana R Manipur ${ }^{4}$
}

${ }^{\mathbf{1}}$ Assistant Professor, ${ }^{2}$ Junior Resident, ${ }^{3}$ Professor and HOD, ${ }^{4}$ Junior Resident, Dept. of Ophthalmology, Hassan Institute of Medical Sciences, Karnataka, India

*Corresponding Author:

Email: lakshmibr24@gmail.com

\begin{abstract}
Aim: To describe fundus manifestations following typhoid fever and their response to systemic steroids.

Materials and Methods: A retrospective study was done on 14 patients during April 2015-Feb 2016 presenting with complaints of diminution of vision with history of typhoid fever 4-6 weeks ago. All patients underwent a detailed ophthalmic evaluation. OCT and FFA were done when considered relevant. TC/DC/ESR/ HIV and Widal tests were done. Oral prednisolone, $1 \mathrm{mg} / \mathrm{kg} / \mathrm{day}$ was given and tapered over a period of 6 weeks.

Results: 21 eyes of 14 patients presenting with visual complaints following typhoid fever were studied. At presentation, vision was $<1 / 60$ in 2 eyes, 1/60-3/60 in3 eyes.3/60 to 6/60 in 12 eyes and 6/60-6/12 in 4 eyes. Fundus manifestations included disc involvement in 15eyes, Retinitis patches in 19 eyes, Vasculitis in 12 eyes and macular edema/star/detachment in 17 eyes. All the findings were confined to the posterior pole. All patients responded well to steroids. Patients with bilateral confluent retinitis had significantly high Widal titres. Final vision ranged between 6/12-6/60.

Conclusion: Even though a less documented entity, one can encounter non-infectious immune mediated retinitis after typhoid fever. This study highlights the need for a high index of suspicion to diagnose this condition and early institution of steroids for better visual outcome.
\end{abstract}

Keywords: Steroids, Post-febrile neuroretinitis, Typhoid, Post-typhoid retinitis, Widal titres.

\section{Introduction}

Ocular involvement is occasional seen following fevers due to various etiologies. The spectrum of ocular manifestations following febrile episode includes conjunctival congestion, uveitis, episcleritis, neuroretinitis, retinitis, and dacryoadenitis. ${ }^{1}$ The trend of post-fever neuroretinitis is on rise due to undocumented reasons.

Posterior segment involvement can be seen in form of retinitis, optic disc involvement and subsequent macular involvement. Neuroretinitis is a particular form of optic neuropathy characterised by acute unilateral visual loss in the setting of optic disc swelling and hard exudate arranged in a star figure around the fovea. ${ }^{2}$ This can be either due to infectious, parainfectious or idiopathic in etiology. ${ }^{3}$

Etiology of febrile illnesses causing neuroretinitis may be viral, bacterial, protozoal or parasitic. The common infections that cause neuroretinitis are catscratch disease, spirochetoses especially syphilis, Lyme disease, and leptospirosis. Cat-scratch disease accounts for two thirds of cases. Additional causes include toxoplasmosis, mumps, salmonella, tuberculosis, and histoplasmosis. ${ }^{4}$ Viral fevers like, chikungunya, ${ }^{5}$ herpes, varicella $^{6}$ causing neuroretinitis has also been documented. Ocular involvement may be due to direct invasion by the pathogen or immune-mediated mechanisms. The given period of latency following the febrile episode points towards an immune mediated phenomenon. Similar picture following typhoid fever is less documented and its increased incidence with neuroretinitis is a cause of concern. This study is undertaken to study post-typhoid neuroretinitis, its manifestations and appropriate management.

\section{Objectives of the Study}

1. To describe fundus manifestations following typhoid fever.

2. To monitor the response of retinitis to systemic steroids.

3. To describe the association of Widal titres with severity of disease.

\section{Materials and Methods}

A retrospective cohort study was conducted on patients presenting to ophthalmic outpatient, in the study period of April 2015 to Feb 2016. The cohort included a series of patients who had a history of diminution of vision following typhoid fever. The study adheres to the tenets of declaration of Helsinki and it was approved from institutional ethical committee, HIMS.

Patients presented with ocular symptoms following typhoid fever were recruited into the study (purposive sampling). The time duration between fever episode and ocular complaints was 3 to 6 weeks. Widal titres were noted from patients case records and these were considered to be raised if $0-\mathrm{Ag} \geq 1: 160, \mathrm{H}-\mathrm{Ag} \geq 1: 80, \mathrm{AH} /$ $\geq 1: 40$. Patients with fever of unknown etiology or diagnosed etiology other than typhoid were excluded from the study. Similar fundus pictures due to other etiologies were excluded. 
Methodology: A total of 14 patients were recruited into the study after applying the above criteria. All patients had history of typhoid fever based on raised Widal titres and was treated for the above. Widal titres were repeated at ophthalmic presentation.

All patients underwent detailed ophthalmic evaluation which included vision testing for near and distance, best corrected visual acuity (BCVA), colour vision, intraocular pressure, pupillary reactions and fundoscopy. Optical coherence tomography, fundus fluorescein angiography were done when required. Fundus manifestations of all the patients were documented in ZEISS fundus camera. Basic investigations included complete hemogram, erythrocyte sedimentation rate, Widal test, venereal disease research laboratory tests (VDRL), human immunodeficiency virus (HIV) ELISA, RA Factor, C-reactive protein, random blood sugars and Mantoux test. Other investigations like dengue serology, peripheral smear for malarial parasite; antinuclear antibodies were ordered when required. Widal titres from previous records and repeat Widal test done during ophthalmic presentation were compared.

All patients were given oral steroids (prednisolone acetate) $1 \mathrm{mg} / \mathrm{kg} / \mathrm{day}$ after obtaining physician fitness. Steroids were given for 6-8 weeks depending on response in a tapering dose. Injection IV methyl prednisolone [1gm/day for 3 days] along with oral steroids was given in 3 patients who had severe bilateral macular involvement with poor vision. Posterior Subtenon injection of triamcinolone acetonide was given in one patient for severe persistent lesions even after 6 weeks of steroid therapy. Topical anti-inflammatory eye drops in the form of nepafenac 3 times a day was prescribed to all patients. Patients were followed up at regular intervals for duration of 3 months. At each visit, BCVA, anterior and posterior segment evaluation and fundus photography was performed. Clinical response was assessed based on BCVA, resolution of posterior segment findings like retinitis and macular edema.

\section{Observations and Results:}

A total 21 eyes of 14 patients ( 7 unilateral, 7 bilateral) were assessed. The mean duration of presentation of ophthalmic manifestations after typhoid fever (period of latency) ranged between 3-6 weeks. The average age of the patients was $41.57 \pm 16.26$ years. There were 7 males (50\%) and 7 females (50\%) showing no gender based variations. A comparison of unilateral and bilateral cases at baseline together with patient characteristics is summarized in Table 1.

Table 1: Comparison of unilateral and bilateral cases at baseline

\begin{tabular}{|l|c|c|}
\hline \multicolumn{1}{|c|}{ Parameters } & Unilateral & Bilateral \\
\hline Age & 43.71 years & 39.93 years \\
\hline Gender & Males -4 & Males -3 \\
& Females -3 & Females-4 \\
\hline Period of latency & 31 days & 39 days \\
\hline Widal & $1: 80-1: 160$ & $>1: 160-1: 320$ \\
\hline
\end{tabular}

Visual acuity at presentation ranged between 1/60 to hand movements. However with treatment, quantitative vision improvement by atleast 2 snellen lines was noted. An overal visual improvement with every visit is represented in graph-1.

\section{Graph 1: Visual acuity improvement}

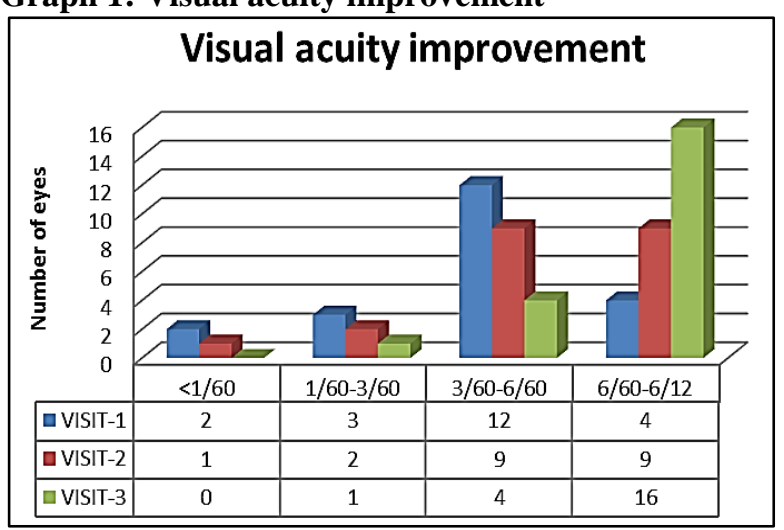

Widal titres which were repeated after the period of latency were compared with previous Widal titres and it was noted that 5 patients had equivocal Widal titres at ophthalmic presentation whereas rest 9 patients had raised titres even after the 3-6 weeks. Table 2 compares the Widal titres during febrile episode and during the ophthalmic presentation.

Table 2: Showing comparison of Widal titres during fever and at ophthalmic presentation

\begin{tabular}{|l|c|c|}
\hline $\begin{array}{c}\text { Widal titres } \\
\text { O/H antigens }\end{array}$ & $\begin{array}{c}\text { During febrile } \\
\text { episode }\end{array}$ & $\begin{array}{c}\text { At ophthalmic } \\
\text { presentation }\end{array}$ \\
\hline $\begin{array}{l}1: 80 / 1: 80 \\
\text { (equivocal) }\end{array}$ & 0 & 5 \\
\hline $1: 160 / 1: 160$ & 6 & 4 \\
\hline $1: 320 / 1: 160$ & 8 & 5 \\
\hline Total & 14 & 14 \\
\hline
\end{tabular}


Graph 2: Comparison of Widal titres

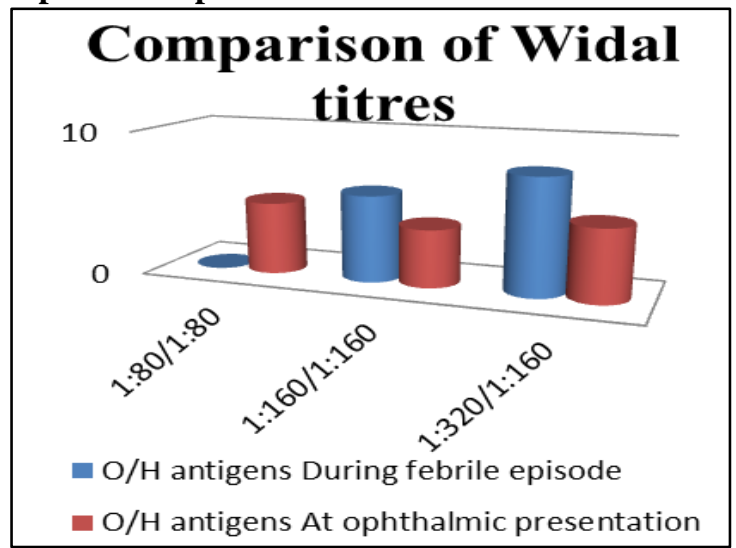

Various fundus manifestations of post-typhoid neuroretinitis included disc involvement in the form of hyperemia; (Table 3, Fig. 1) edema or sphincter hemorrhages were seen in 15 eyes. Retinitic patches observed as yellowish fluffy retinal exudates concentrated in posterior pole was seen in 19 eyes. Macular involvement, either as edema or neurosensory detachment was seen in 17 eyes. Vasculitis was noted in 17 eyes. One patient had an atypical presentation of bilateral papillitis without any retinitic patches. It can be noted that all the manifestations were typically confined to posterior pole.

Table 3: Showing various fundus manifestations of post-typhoid retinitis.

\begin{tabular}{|l|c|}
\hline \multicolumn{1}{|c|}{ Fundus manifestations } & Number of eyes \\
\hline Disc involvement & 15 \\
\hline Retinitis & 19 \\
\hline Vasculitis & 12 \\
\hline Macular involvement & 17 \\
\hline
\end{tabular}

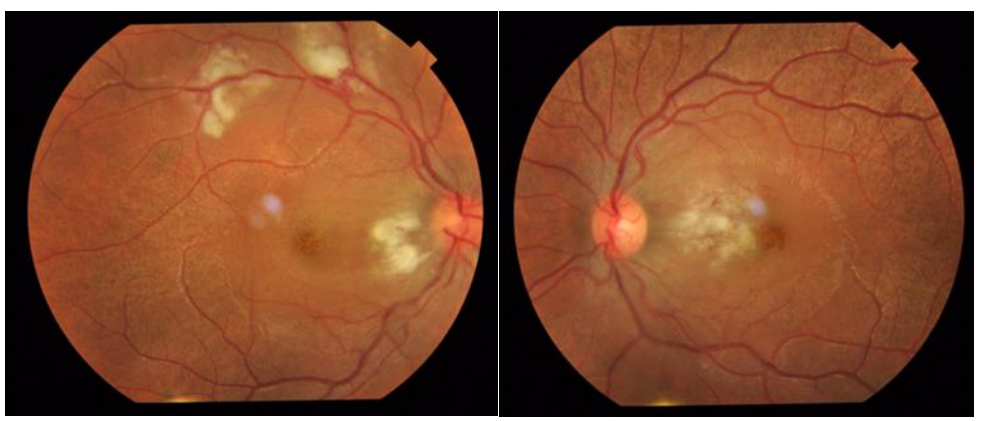

Fig. 1: Severe bilateral post-typhoidneuroretinitis with retinitic patches and neurosensory detachment at macula(associated with high Widal titres)

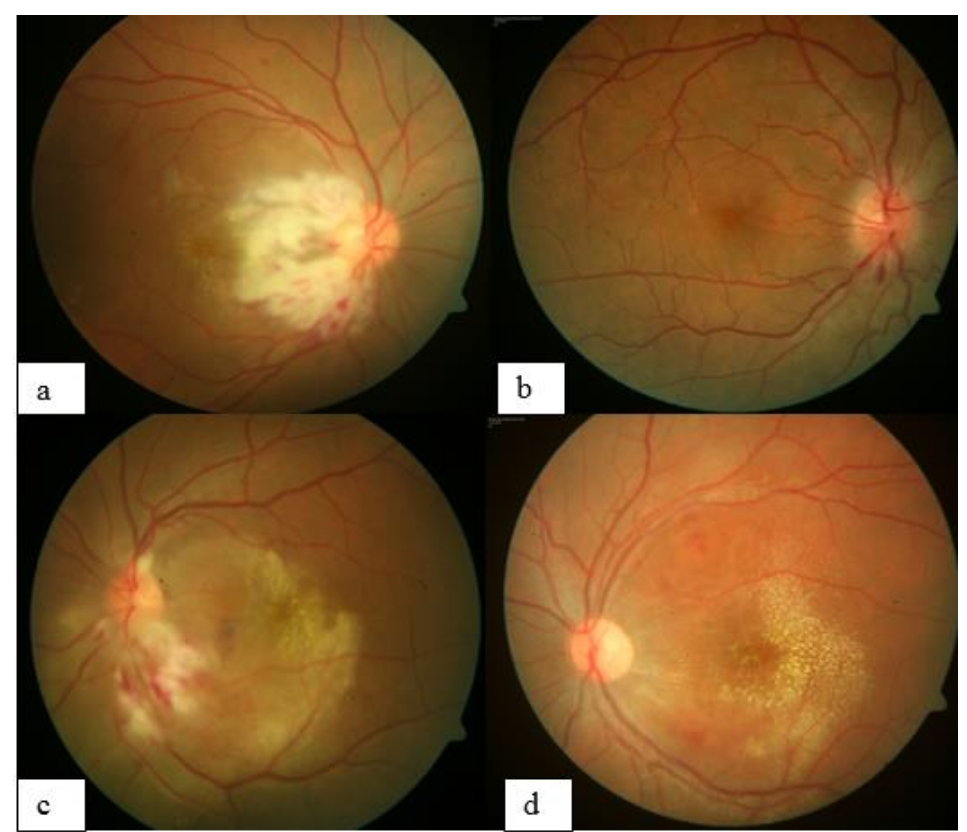

Fig. 2a: Extensive retinitis involving posterior pole; (b: Disc involvement-hyperemia and disc hemorrhage; (c: Retinitits in inferior quadrant with severe macular involvement; (d: Rea=solving neuroretinitis with with macular star. Note all the manifestations in confined to posterior pole 

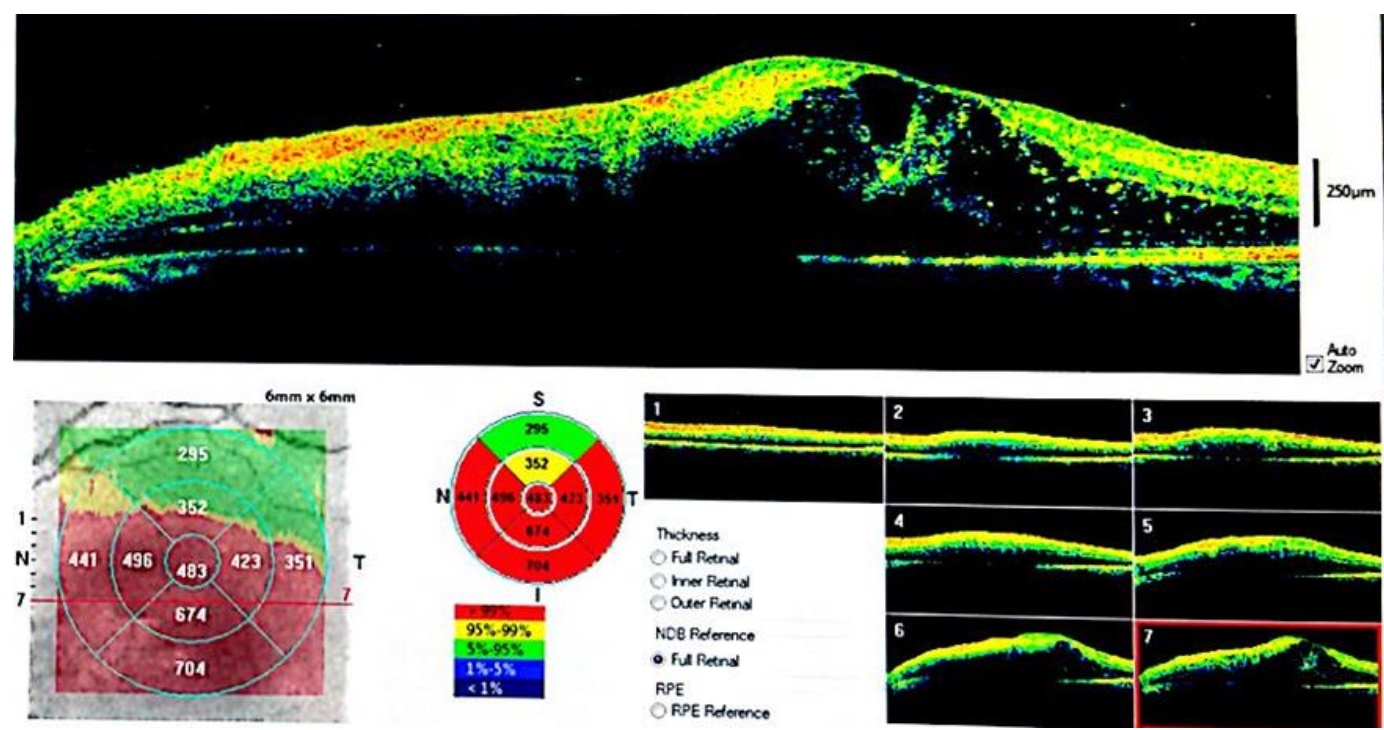

Fig. 3: Optical Coherence Tomography showing neurosensory detachment

On evaluating the response to steroids for the above mentioned duration, all 14 patients responded positively in a variable manner. Post-treatment visual acuity ranged between $6 / 60$ to $6 / 12$ in most of the cases and the fundus

lesions almost resolved leaving retinal pigment epithelial changes and foveal thinning at the macular region in cases with severe macular involvement. This favourable response to systemic steroids points towards an underlying immunological mechanism for this entity.

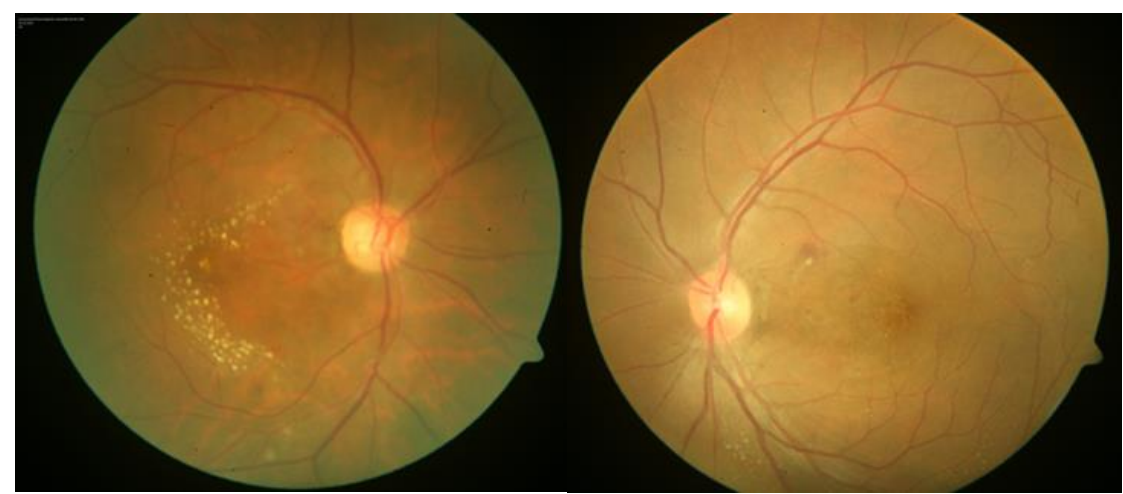

Fig. 4: Resolution of fundus lesions after steroids with minimal residual pigmentary changes and exudates at macula

For correlation of widal titres with ocular disease severity - extent of fundal lesions, visual acuity and laterality were considered. We graded the disease severity on the basis of pre-mentioned fundal lesions. Disease was considered extensive when 3 out of 4 components that included disc involvement, retinitis, vasculitis and macular involvement were seen. Widal titres were considered to be high when $\mathrm{O} / \mathrm{H}$ antigen is $>1: 160$ at ophthalmic presentation. Based on the above findings, it was found those 7 patients with bilateral disease and 14 eyes with visual acuity $<6 / 60$ were found to have high Widal titres.

Table 4: Widal titres variation among unilateral and bilateral cases at ophthalmic presentation

\begin{tabular}{|l|c|c|}
\hline Widal Titres & Unilateral & Bilateral \\
\hline High & 2 & 7 \\
\hline Equivocal & 5 & 0 \\
\hline
\end{tabular}

Out of 14 patients- 9 had extensive lesions associated with high Widal titres, while 5 patients with less severe disease had equivocal Widal titres.

Table 5: Corelation of Widal titres with visual acuity at ophthalmic presentation

\begin{tabular}{|l|c|c|}
\hline Widal Titres & $\begin{array}{c}\text { Visual acuity } \\
\mathbf{< 6 / 6 0}\end{array}$ & $\begin{array}{c}\text { Visual acuity } \\
\mathbf{> 6 / 6 0}\end{array}$ \\
\hline High & 14 & 2 \\
\hline Equivocal & 3 & 2 \\
\hline
\end{tabular}

Hence it was observed that High Widal titres were associated bilateral involvement, extensive lesions and poor visual acuity which was found to be statistically significant. [Fisher exact test, p-0.021]

\section{Discussion}

Typhoid fever caused by salmonella typhi leads to enteric fever, septicemia, and gastroenteritis and rarely 
affects the eye. Involvement of eye may be due to direct invasion or immune mediated phenomenon. ${ }^{3}$ Typhoidrelated uveal complications includes iritis, retinal hemorrhage, choroiditis, endophthalmitis and panophthalmitis. $^{7}$

Ocular manifestations typically occur 3-4 weeks following the episode of typhoid fever. Given the timing of late onset, high Widal titres even at ophthalmic presentation and improvement with systemic steroids points towards the diagnosis of post-typhoid immunemediated retinitis. Pathogenesis of immune-mediated vasculitis could be attributed to post infectious immunologic effects which may lead to an immune response that reacts to self-antigens (for example, heat shock protein and myelin basic protein) or homology between retinal antigens and microbial peptides (similarity between $\mathrm{S}$ antigen and microbial peptides like yeasts, Escherichia coli, and hepatitis B virus) or molecular mimicry leading to autoimmunity ( $\mathrm{S}$ antigen and interphotoreceptor retinoid binding protein - IRBP). ${ }^{8}$

Various studies have documented post fever retinitis and various etiologies relating to it. In a single centre study in south India consisting of series of 14 cases of post-fever retinitis of various etiologies, only one case was reported following typhoid fever. ${ }^{1}$ Similar reports also exist on post viral fever following dengue and chikungunya. Further individual case reports have documented the aftermath of typhoid fever consisting of similar picture of retinitis, vasculitis and neurosensory detachment. $^{9}$

Our study thus represents a cohort of patients with retinitis following typhoid fever. The incidence of this entity after 3-6 weeks post-fever and significant improvement with steroids substantiates our diagnosis of immune -mediated retinitis. Systemic antibiotics were not given in our study since there was no fever at the time of ocular presentation and they were previously treated with anti-typhoid medications. However the possibility of underlying viral etiology could not be excluded. Even though spontaneous recovery is possible in post febrile neuroretinitis, ${ }^{10}$ steroids help in hastening the resolution of retinitis and improving the vision, thus decreasing the time for recovery.

\section{Conclusion}

Post-typhoid neuroretinitis evolves as a significant cause of visual morbidity. However documentation of this entity in literature is rather limited. Younger agegroup and high Widal titres had a significant association with severity of the disease. Even though, spontaneous resolution is possible in mild cases, severe cases may need corticosteroids that help in improvement of symptoms and prevention of visual loss. Role of antibiotics remains controversial.

This study highlights the need for a high index of suspicion by an ophthalmologist to diagnose this entity in patients presenting with visual loss following typhoid fever and for early institution appropriate therapy.
However large sample sized studies is further needed in this domain.

\section{References}

1. Vishwanath S, Badami K, Sriprakash KS, Sujatha BL, Shashidhar SD, Shilpa YD. Post-fever retinitis: a single center experience from south India. International ophthalmology. 2014;34(4):851-7.

2. Maitland CG, Miller NR. Neuroretinitis. Arch Ophthalmol. 1984;102(8):1146-50.

3. Relhan N, Pathengay A, Albini T, Priya K, Jalali S, Flynn HW. A case of vasculitis, retinitis and macular neurosensory detachment presenting post typhoid fever. $J$ Ophthalmic Inflamm Infect. 2014;4(1):23.

4. Srinivasan R, Kaliaperumal S. Neuroretinitis-Review. KJO-Changing Times.:7.

5. Murthy KR, Venkataraman N, Satish V, Babu K. Bilateral retinitis following Chikun-gunya fever. Indian $J$ Ophthalmol. 2008;56(4):329.

6. Madhavan HN, Priya K. The diagnostic significance of enzymelinked immunosorbent assay for herpes simplex, varicella zoster and cytomegalovirus retinitis. Indian J Ophthalmol. 2003;51(1):71-75.

7. Duke-Elder S, Perkins ES (1968) Diseases of the Uveal Tract, 9th edn. London: Kimpton.

8. Hughes EH, Dick AD. The pathology and pathogenesis of retinal vasculitis. Neuropathol Appl Neurobiol. 2003;29(4):325-340.

9. Laul R, Atif Ali MI, Shafi S. Typhoid aftermath: presenting as vasculitis, neuroretinitis and macular neurosensory detachment. International Journal of Medical Research \& Health Sciences. 2015;4(3):737-9.

10. Biradar S, Warad VG. Spontaneous resolution of severe neuroretinitis following a febrile illness. US National Library of Medicine enlisted journal. Al Ameen J Med Sci. 2015;8(2):164-167.

How to cite this article: Acharya $\mathrm{P}$, Ramamurthy LB, Venugopal KC, Manipur SR. Evaluation of posterior segment manifestations following typhoid fever-a clinical study. Ind J Clin Exp Ophthalmol. 2018;4(3):421-425. 